\title{
Carbonvestments: Appraising Investments in a Carbonomics Environment
}

\author{
Janek Ratnatunga ${ }^{\mathrm{a}}$ and Chris D'Souza ${ }^{\mathrm{b}}$ \\ ${ }^{\text {a }}$ Calwest University, USA \\ ${ }^{\mathrm{b}}$ Institute of Certified Management Accountants, Australia
}

\begin{abstract}
In 2011, Australia introduced a Carbon Pollution Reduction Scheme (or CPRS) that was a cap-and-trade emissions trading scheme for anthropogenic greenhouse gases. It clearly indicated to companies that polluting the environment with carbon emissions will no longer be free. Companies subject to carbon caps under a carbon trading scheme can either invests in carbon sequestration project and or buy carbon credits to offset their carbon liabilities. While Net Present Value (NPV) has been recorded as the most popular appraisal technique used across the globe for project valuation purposes, finance theorist suggests that using real options (RO) analysis is a more superior techniques to value investment opportunities. Using case study data of an early mover in a CPRS scheme, this paper reveals how RO approach provides more strategic insights than traditional NPV in valuing carbon sequestration investments (termed carbonvestments).
\end{abstract}

Keywords: Carbon Emissions; Carbonomics; Net Present Value; Project Valuation; Real Options Analysis

\section{Introduction}

\subsection{The Greenhouse Effect}

Earth and all life that occupies it, require the gases- water vapour, methane, ozone, carbon monoxide, nitrous oxide and carbon dioxide (CO2). The Earth manages to regulate concentrations of greenhouse gases through a system of sources and sinks. In nature, carbon is sourced or emitted by burning and rotting of vegetation and other organic matter (called Carbon Sources). Conversely, $\mathrm{CO} 2$ is absorbed (or sequestered), by trees, plankton, soils and water bodies, which are termed 'Carbon 
Sinks'. This "greenhouse effect" is currently in imbalance due to: (a) the burning of fossil fuels like oil; (b) accelerated land clearance; (c) urbanisation, and (d) increased living standards.

The balance of scientific evidence indicates that the world is facing significant risks associated with the potentially damaging consequences of climate change. Although there is a debate raging about the 'true-cause' of climate change, the strict criteria of evidence-based science is now being replaced by knowledge construction using the Precautionary Principle which reverses the burden of proof and encourages a precautionary response when there is insufficient knowledge to initiate preventative and control reactions (Snedeker, 2003). In simple terms, the principle states that "it is better to be safe than sorry".

Under this principle, the imbalance in greenhouse gas emissions calls for greater attention and precautionary measures to be implemented. The debate on how best to tackle changes to the climate perceived to be impacted by human activity has two distinct but interrelated approaches. These are called 'start of pipe' and 'end of pipe' solutions. ${ }^{1}$ The former 'start of pipe' solution relies on finding alternative sources to power our industries, buildings and motor vehicles. These include using wind, solar, geo-thermal, waves, vegetables (bio) and nuclear instead of high carbon emitting sources such as coal and petroleum.

The latter 'end of pipe' solution relies on the behaviour modification of countries, organizations and individuals to reduce the consumption of power that needs to be obtained from high carbon emitting sources, i.e. reduce the carbon footprint. Both solutions also have two underlying catalysts for change: ethical, because It is the right thing to do, and economical because we can save money. Those that call for an ethical response, follow the views espoused by Schumacher (1997) and argue that countries, organizations and individuals should use alternative energy sources and reduce their carbon footprint because it is the "moral and ethical thing to do" regardless of economic consequences. However, this ethical response has been largely lacking in countries that have placed no

\footnotetext{
${ }^{1}$ The 'catalytic converter' placed at the end of a pipe of an engine that could run only highly leaded gasoline (in order to reduce pollution from that engine) is an example of an 'end of pipe' solution. The longer-term solution was at the start of the pipe, i.e. by making engines that run on unleaded gas.
} 
economic initiatives on either start or end of pipe solutions (Murphy, 2009). The international clarion call has instead been for an economic solution.

\subsection{Carbon Ethics and Carbonomics}

Some economists have questioned if we need an economic solution. The "Schumacherian ideal" states that we should reduce our carbon footprint purely on moral grounds (Barber, 2007). In other words, we need to reduce pollution purely because it is important for humankind (and not for any economic reasons). We do this by good carbon behaviour (ethical solutions), by reducing our carbon footprint via lifestyle changes. In these "end-of-pipe solutions" it does not matter how the electricity is produced - even burning of coal - if we reduce our consumption, then there will be less demand to burn coal.

Several lifestyle changes (from countries, organisations and individuals) are needed to achieve a substantial decrease in emissions such as reduced energy demand; increased energy efficiency; using fewer fossil fuels and more renewable energy sources (see Tables $1 \& 2$ ). It will also require research and development of sustainable technologies that reduce $\mathrm{CO} 2$ emissions.

There is a view developing in some businesses, however, that there is a direct measurable correlation between lifestyle changes, environmental efficiency and economic results (e.g. clean air leads to healthier workers leads to more productivity). However, most of the studies show that companies have been slow to implement these Ethical solutions. This required an economic solution.

The problem is that our 21st century 'needs' are still being met with 18th century 'power' (from coal and petroleum). Thus, there needs to be economic incentives for the development of sustainable technologies that reduce $\mathrm{CO} 2$ emissions; (a) wind farms; (b) geothermal; (c) water (hydro and ocean waves); and (d) nuclear. These are called 'start-of-pipe solutions' in that if we find alternative sources of low carbon emission power, we need not change our current lifestyles radically. 


\section{Management Accounting Frontiers 2 (2019) 31 - 68}

Table 1. Carbon Reduction Methods for Individuals

Get blueprints for a green house

Change light bulbs to low emission

Pay the carbon offsets when Buying

Move from the mansion

Hang up a clothesline

Give new life to your old warm clothes

Use more geothermal heat

Take another look at vintage clothes

Work close to home

Ride the bus

Move to a high-rise building

Pay your bills online

Open a window (natural cooling)

Ask the experts for an energy audit of your home

Buy green power, at home or away

Wear products made from renewable resources

Properly insulate your water heater

Avoid the meat products

Be aggressive about passive houses
Fly straight between locations

Support your local farmer

Plant a bamboo fence

Have a green wedding (i.e. buy locally)

Remove the tie (casual business attire)

Drive green on the using bio-fuel cars

Say no to plastic bags

Switch off the lights at quitting time

Shut down your computer

End the paper chase

Think outside the packaging

Trade carbon for capital

Make your garden grow

Check the label (cheap prices for overseas products because no carbon costs are paid)

Fill car up with passengers

Rake in the fall colours (not leaf blowers)

Check your tires

Set a personal carbon budget

Consume less, share more, live simply 


\section{Management Accounting Frontiers 2 (2019) 31 - 68}

Table 2. Carbon Reduction Methods for Businesses

Change lightbulbs to low emission

Pay the carbon tax

Build a skyscraper

Turn up the geothermal heat

Capture the carbon

Let employees work close to home

Pay your bills online

Open a window

Ask the experts for an energy audit

Buy green power

Remove the tie (Every day is casual Friday)

Fly straight to location

Copy California's state emission levels

Turn food into fuel (biofuels)
Shut down computers (no standby)

Switch off the lights at quitting time

End the paper chase

Play the market

Think outside the packaging

Trade carbon for capital

Set an organisational carbon budget

Pay for your carbon sins

Make one right turn after another

Plant a tree in the tropics

Drive green (change company vehicles to biofuels)

If you must burn coal, do it right

Set a higher carbon emission standard

Illuminate public spaces with LEDs

\subsection{Kyoto Protocol and the Paris Agreement}

In the 1990s over 150 countries agreed to strive to decrease CO2 emissions, accounting for an estimated 55 percent of global greenhouse gas emissions (called the Kyoto Protocol). The Protocol's first commitment period started in 2008 and ended in 2012. A second commitment period (2012-2020) was agreed in 2012 in what is known as the Doha Amendment. 
The first international economic/regulatory response, based on the precautionary principle, has been the Kyoto Protocol, under which now 178 countries have agreed to strive to decrease their $\mathrm{CO}_{2}$ emissions. ${ }^{2}$ The Kyoto Protocol, with Carbon Trading as one of its key social constructions, is an economic catalyst for both start of pipe and end of pipe solutions,

Negotiations were held in the framework of the yearly UNFCCC Climate Change Conferences on measures to be taken after the second commitment period ends in 2020. This resulted in the 2015 adoption of the Paris Agreement, which is a separate instrument under the UNFCCC rather than an amendment of the Kyoto Protocol. A signatory country can emit more $\mathrm{CO} 2$ than its assigned amount only if it can simultaneously sequester the equivalent amount in 'allowable' carbon sinks. These include afforestation and reforestation activities undertaken since 1990.

Currently many nations are grappling with how best to implement the Paris Agreement with least impact to their economies. Under the Kyoto Protocol, which is valid till 2020, a country can emit more $\mathrm{CO}_{2}$ than its assigned amount only if it can simultaneously sequester the equivalent amount in 'allowable' carbon sinks, which include afforestation and reforestation activities undertaken since 1990 (i.e. 'incremental'). ${ }^{3}$ Australia ratified the Kyoto protocol in 2007 and the Paris Agreement in 2015. ${ }^{4}$ The United States signed the Paris Agreement under President Barack Obama, but pulled out of it under President Donald Trump. The United States is the only major developed country that remains uncommitted to the Paris Agreement.

\footnotetext{
${ }^{2}$ We have used carbon dioxide $\left(\mathrm{CO}_{2}\right)$ in this paper for simplicity and readability purposes, although the reduction required is actually of 6 greenhouse gases (GHGs) in terms of their $\mathrm{CO}_{2}$ equivalents $\left(\mathrm{CO}_{2}-\mathrm{e}\right)$.
}

${ }^{3}$ These must be 'incremental', i.e. a new tree planted. Pre-1990 trees still existing are not considered as sinks for carbon credit purposes, as they have reached maturity and are in 'balance' as to the amount of carbon sequestered and emitted. Some developed countries are giving developing countries 'grants' to use in preventing illicit logging. Such grants are outside the Kyoto protocol.

\footnotetext{
${ }^{4}$ Developing countries, including China, India and Indonesia, have ratified the protocol but are 'exempted' from reducing $\mathrm{CO}_{2}$ emissions under the present agreement, despite their large populations, and high emissions levels. China ranks only behind the USA in carbon emissions, and in some rankings is the number one emitter. Australia, despite being the largest 'per-capita' polluter, has negotiated an annual target of $108 \%$ of its 1990 emissions during the 2008-2012 period.
} 
The Kyoto Protocol developed various alternative mechanisms for reducing carbon emissions that would enable developed countries with quantified emission limitation and reduction commitments to acquire greenhouse gas reduction credits. Amongst these mechanisms is the establishment of an International Emission Trading (IET) scheme. Here countries can trade in the international carbon credit market. Countries with surplus credits can sell them to countries with quantified emission limitation and reduction commitments under the voluntary emission targets accepted under the Kyoto Protocol.

Those countries with emissions reduction target, will in turn set up a cap-and-trade scheme to pass on these pollution limits to business entities who are told how much $\mathrm{CO}_{2}$ they can emit (the cap). Two carbon emissions reduction project-based mechanisms include Joint Implementation (JI) by at least two developed countries and a Clean Development Mechanism $(C D M)$ which must be implemented in the region of developing countries. Both create carbon units known as Emissions Reduction Unit (ERU) and Certified Emissions Reduction (CER), respectively, which can be traded in an emissions trading scheme (ETS) as the third market mechanism. If companies emit more than their "cap" they can buy $C E R s^{5}$ from other businesses that come in under their cap (the trade). ${ }^{6}$ Trade takes place in an over the counter market, or via a Carbon Credit Exchange trading market. The emergence of a market which determines a price for the right to pollute, has resulted in a carbonomics era, in which economic decisions are made based on organisations' GHG emission targets (Ratnatunga \& Balachandran, 2009).

\subsection{The Kyoto Protocol Today}

In 2016, when the Paris Climate Agreement went into force, the United States was one of the principal drivers of the agreement, and President Obama hailed it as "a tribute to American leadership." As a candidate for president at that time, Donald Trump criticised the agreement as a bad deal for the American people and pledged to withdraw the United States if elected, which he followed through with.

${ }^{5}$ Each CER represents one metric tonne of $\mathrm{CO}_{2}$ equivalent $\left(\mathrm{tCO}_{2}\right.$-e) either removed from the atmosphere or saved from being emitted.

${ }^{6}$ Also called Australian Carbon Credit Units (ACCU) in Australia. 
In 2019, the dialogue is still alive but has turned into a complex quagmire involving politics, money, lack of leadership, lack of consensus, and bureaucracy. Today, despite myriad plans and some actions, solutions to the problems of GHG emissions and global warming have not been implemented.

Almost all scientists who study the atmosphere now believe that global warming is primarily the result of human action. Logically then, what humans have caused by their behaviour should be able to be remedied by humans changing their behaviour. It is frustrating to many that cohesive action to deal with the human-made global climate crisis has yet to happen. It is up to individual companies to undertake investments that can reduce the impact of our actions of the climate.

\subsection{Investments under the Kyoto Protocol and the Paris Agreement}

From a firm-centric point of view, if subject to a government imposed rationing scheme, a number of options are available to manage its emissions liability: (1) do nothing and buy carbon credits from the government or from a carbon market to make up the shortfall; (2) reduce its carbon liability by undertaking internal projects that use new technologies to lower the carbon emissions of its resources and activities; (3) invest in external projects (e.g. wind farms; reforestation, etc.) that sequester carbon in order to offset its carbon liability and sell excess carbon credits generated (if any) in emission trading markets; or (4) a combination of both internal and external investments. Decisions to make such both internal and external investments in carbon management projects, termed carbonvestments, fall under the general area of capital budgeting.

\subsubsection{Capital Budgeting}

Capital budgeting is the process of valuing and choosing investment projects to allocate firms' capital. It has been widely discussed in the conventional finance literature, where it is documented that the underlying methodology of investment decision making has shifted from relying mainly on business experience and intuition (Pollard, 1965) into incorporating the use of sophisticated financial management techniques (Haka, 2007). 
Ideally, businesses would pursue all projects and opportunities that enhance shareholder value. However, because the amount of capital any business has available for new projects is limited, management uses capital budgeting techniques to determine which projects will yield the best return over an applicable period.

Some methods of capital budgeting companies use to determine which projects to pursue include throughput analysis, net present value (NPV), internal rate of return, discounted cash flow, and payback period.

Throughput analysis is the most complicated form of capital budgeting analysis but also the most accurate in helping managers decide which projects to pursue. Under this method, the entire company is considered as a single profit-generating system. Throughput is measured as an amount of material passing through that system.

The analysis assumes that nearly all costs are operating expenses, that a company needs to maximise the throughput of the entire system to pay for expenses, and that the way to maximise profits is to maximise the throughput passing through a bottleneck operation. A bottleneck is the resource in the system that requires the longest time in operations.

This means that managers should always place a higher priority on capital budgeting projects that will increase throughput passing through the bottleneck.

Discounted cash flow (DCF) analysis looks at the initial cash outflow needed to fund a project, the mix of cash inflows in the form of revenue, and other future outflows in the form of maintenance and other costs.

These costs, except for the initial outflow, are discounted back to the present date. The resulting number from the DCF analysis is the net present value (NPV). Projects with the highest NPV should rank over others unless one or more are mutually exclusive.

Payback analysis is the simplest form of capital budgeting analysis, but it is also the least accurate. It is still widely used because It is quick and can give managers a "back of the envelope" understanding of the real value of a proposed project.

This analysis calculates how long it will take to recoup the costs of an investment. The payback period is identified by dividing the initial investment in the project by the average yearly cash inflow that the project will generate. 
Of all of the above capital budgeting techniques available for project evaluation, Net Present Value (NPV) is the most popular methodology used, in which expected future net-cash flows are discounted to present values using the firm's weighted average cost of capital (WACC) (see Bennaouna, Meredith \& Marchant 2010; Haka 2007). However, a straightforward NPV approach does not consider the managerial flexibility that is embedded in most investment opportunities, such as the possibility of delaying a decision until more information is obtained or the underlying assumptions of the situation change.

\subsubsection{Real Options}

Due to the existence of managerial flexibility that is embedded in most investment opportunities, finance theorists recommend the use of real options (RO) analysis in projects that currently have significant uncertainty but may be re-visited at a later date if the uncertainty reduces (Dixit \& Pindyck, 1995; Myers, 1977; Smith \& Nau, 1995; Trigeorgis, 1996). The use of options for investment decision making in the financial markets has been extensive. However, while the discourse pertaining to the RO approach has been intense in the literature and is now covered in most finance textbooks (Damodaran, 2002; 2011; Brealey, Myers \& Allen, 2008), its use in practice in project appraisal decisions seems limited (Bennaouna, Meredith \& Marchant, 2010). This low practical use appears to be mainly because the complex mathematics of real options and the difficulty in identifying and correctly specifying the underlying options (Luehrman, 1998b; Teach, 2003).

While in the financial markets there are set parameters within which share prices can move, enabling one to model possible options if a share price hits a certain value, investment projects do not have such value parameters, as the market for such projects is illiquid. However, with the introduction of an emissions trading system (ETS) or similar future pricing structure, these market-value parameters will be present, thus the RO approach may emerge as a very robust and practical approach to investment appraisal in the carbonomics era.

This paper aims to: (1) contribute to the carbon emissions discourse by specifically focusing on carbon investment appraisal which is an area that is currently under-studied in the literature; (2) draw more attention to the use of real option theory as a framework to better identify and value potential investment opportunities; and (3) offers valuable insights for 
policy makers with regard to the corporate willingness to invest in cleaner technologies or carbon sequestration projects in an carbonomics environment of carbon rationing, carbon credit prices and carbon trading.

To achieve these aims we will apply real options (RO) analysis for carbonvestments valuation in a case study company in order to demonstrate not only that it can be practically applied, but also that it is a more superior technique to NPV in making decisions on carbonvestments. We will also demonstrate that in the real world, the provision of such techniques may assist business entities to make investment decisions which enable their competitive position to be maintained as they move towards a low carbon economy. As emphasised by Ratnatunga and Balachandran (2009), business entities should start considering carbon thinking to facilitate better decisions to be winners in the new world of carbonomics.

This paper will proceed in the following manner. First, it reviews previous studies in investment decisions and carbon emissions and trading. The basic concepts of RO theory are outlined in the following section. The penultimate section presents a data from a case study company to reveal how RO analysis outperforms standard NPV in valuing carbonvestment opportunities. The final section provides the concluding remarks.

\section{Investment Decisions in the Carbonomics Era: A Literature Review}

The business world is moving into the carbonomics era (Ratnatunga, 2007), where carbon pollution will have a price tag to be paid for (Cook, 2009; Harriss, Paton \& Elsayed, 2010; MacKenzie, 2009). One step to gain competitive advantage in the low-carbon future is to be an early mover by factoring carbon business exposure into investment decision making (Parkinson, 2010; Ratnatunga \& Balachandran, 2009; Ratnatunga, Jones \& Balachandran, 2011; Schultz \& Williamson, 2005). This paper aims to link the discourse of investment valuation techniques into the emerging carbon emissions trading field of study. The literature related to these two topics is outlined respectively. 


\subsection{Investment Decisions}

Initially business owners relied merely on their business experience and intuition to assess and decide on investments (Pollard, 1965). Although these factors are still an important basis for making investment decisions, Haka (2007) argues that due to separation of ownership and decision rights, the actors involved in the decisions have now extended to include professional managers. The ownership-management separation appears to trigger the use of capital budgeting and financial management techniques to assist investment appraisal. Haka's review (2007) concluded that the extant studies have documented three prominent techniques to appraise investments, namely discounted cash flow (DCF), payback period (PP) and accounting rate of return (ARR). DCF techniques are clearly the preferred methods in capital budgeting practices utilised by firms surveyed in studies during the 1959-2002 period (Haka, 2007).

Likewise, Bennaouna et al. (2010) reported that survey research between 1960-2010 has conveyed a similar trend, i.e., firms across the globe preferred utilising DCF methods as the main capital budgeting technique. The most favoured of the DCF techniques available are Net Present Value (NPV) and Internal Rate of Return (IRR). Non-DCF techniques, such as PP and ARR, were still utilised, even though with diminishing popularity (Bennaouna, Meredith \& Marchant, 2010). ${ }^{7}$

The lack of popularity in the use of the $\mathrm{RO}$ approach as a technique to appraise investment projects in practice can be contrasted with its substantial theoretical development in the literature (Bennaouna, Meredith \& Marchant, 2010). It should be noted that the sizeable real options literature comprises mainly theoretical works, whereas the empirical studies in terms of project evaluation appear to be lacking (Tong \& Reuer, 2007; Yavas \& Sirmans, 2005). As discussed earlier, with the introduction of an ETS or similar future pricing structure, the decision if to delay, continue or abandon a carbon sequestration project can be evaluated using the RO approach; and thus, the valuation technique appears to have practical possibilities for investment appraisal in the carbonomics era.

A strand of literature has already introduced the use of the RO approach (along with its comparison to basic NPV analysis) for valuing investments in energy sector within the EU ETS. Utilising a hypothetical power plant in Finland for a simulation with different carbon price scenarios, Laurikka and Koljonen (2006) showed that the optimal decision is to delay the

\footnotetext{
${ }^{7}$ There are hybrid techniques such as Discounted Payback Period (DPP).
} 
investment if the carbon price is low and to in invest in a gas plant as opposed to a coal plant if the carbon price is high in the ETS. Another Finnish case study that applied the RO approach on a stochastic price model conveyed that an integrated gasification combined cycle (IGCC), i.e., a lower emissions power generation technology, was costly in power plants retrofits (Laurikka, 2006). These Finish studies concluded that the low carbon price provides a negative incentive to invest in carbon reducing technologies and that RO analysis facilitates better valuation than NPV by incorporating available options under different carbon price scenarios. Furthermore, an illustrative case study on the application of the RO approach for valuing CDM project in South Africa provided a better insight to consider whether to invest right away or to postpone a CDM project, which has been overlooked by conventional NPV analysis (Tyler \& Chivaka, 2011).

\subsection{Carbon Emissions and Trading}

Research on emissions trading was first sparked by a series of field studies undertaken in the $\mathrm{UK}^{8}$ as the 'first-ever national emissions trading scheme' (Roeser \& Jackson, 2002), as well as in the European Union (EU), which currently has a multi-country Emission Trading System (EU ETS) since 2005 (Engels, Knoll \& Huth, 2008). The UK study documented a variety of emissions reporting standards and different reporting periods (Roeser \& Jackson, 2002). In addition, the top UK firms provided disclosure on GHG emission mitigating actions as a response to increased pressure from major institutional investors such as the Carbon Disclosure Project (CDP) and the Institutional Investors Group on Climate Change (IIGCC) (Okereke, 2007).

Some EU studies have attempted to explore various ETS implications for businesses. The EU ETS was launched in two phases: the pilot phase (2005-2007) and the second phase (2008-2012), which concurs with the Kyoto compliance period (Pinkse \& Kolk, 2009). In relation to investment, Egenhofer (2007) argued that the short-term carbon cap allocations in these two phases discouraged corporations to invest in long term carbon-

\footnotetext{
${ }^{8}$ The UK established an emissions trading scheme in April 2002. In addition to the aim of significantly reducing greenhouse gas emissions in accordance with the Kyoto Protocol, the UK ETS also aimed to prepare UK companies with practical experience in emissions trading ahead of the upcoming European trading scheme. The nature of this scheme was voluntary. The UK ETS took place for a five-year period and ended in December 2006.
} 
friendly technologies. His notion was elaborated by Hoffmann (2007) empirical study of the German electrical industry, which revealed that this industry integrates carbon costs into their investment decisions but mainly for small scale and short-term investments.

Much of the above literature conveyed varying degrees of acceptance by corporations on the EU ETS. While some firms merely viewed the ETS as a matter of policy compliance, others took it as an opportunity to gain profits from trading activities. The experience of firms in the UK ETS seemed to encourage them to become the active trading actors in the first phase of the EU ETS, compared to firms residing in Germany, Denmark and the Netherlands (Engels, Knoll \& Huth, 2008). Many firms subjected to the EU ETS in Germany, the UK, the Netherlands, and Denmark utilised both internal and external advice to handle ETS compliance. These companies combined insights from relevant company units and external expertise, such as consulting firms, industrial associations and research institutions, as well as from workshops to develop strategic responses to ETS (Engels, 2009).

In terms of reporting on the impact of carbon emissions trading schemes (such as the EU ETS) on corporate performance and valuation, the discussion in the academic and professional literature has been rather disjointed. Freedman and Jaggi (2005) undertook early academic work on the Kyoto protocol by looking at the accounting disclosures of the largest global public firms in polluting industries. A year later, Kundu (2006) examined financial aspects of carbon trading in a professional journal article.

Ratnatunga (2007) integrated the academic and professional discourse by highlighting the difficulties that the accounting and assurance professions are having in measuring, reporting and verifying the monetary values of carbon credits bought and sold in Emission Trading Schemes. Bebbington and Larrinaga (2008) undertook a closer inspection of the risks and uncertainties that arise from global climate change initiatives and discussed the benefits of remaining within a non-financial accounting and reporting framework with regards to carbon; and Callon (2008) discussed the many controversies regarding carbon trading schemes and related measurement schemes.

In terms of internal reporting, Ratnatunga and Balachandran (2009) considered the impact of carbon trading on the strategic cost management and strategic management accounting information systems. Here they briefly looked at the capital budgeting implications of efficient carbon 
management (ECM), especially the valuation premium that would be given to investments in ECM, such as investments in alternative energy assets and abatement activities such as wind, biomass, solar, geothermal, and nuclear.

Ratnatunga and Balachandran (2009) also pointed out that if the equity and debt markets may value-discount carbon intensive businesses (causing high financing costs) and place a value-premium on low carbon emitting businesses (causing low financing costs); and that if such financing of carbon related investments can be isolated, then there would be a need to calculate an organisation's carbon related cost of equity $\left(K_{e}\right)$ and cost of debt $\left(K_{d}\right)$ in order to calculate its overall Carbon-WACC $\left(K_{o}\right)$ for discounting of carbon related net cash flows. However, despite some discourse such as the above on carbonvestment appraisal, the use of the RO approach as the preferred investment appraisal technique to assist business entities handling risk within an environment of an uncertain carbon emission permit price remains extremely limited, with a focus mainly on energy sector (for example Laurikka 2006; Laurikka \& Koljonen 2006). As the application of the RO approach to assist firms in investment valuation decisions seems promising, the theory on which this approach is based will be discussed in the next section.

\section{Real Options (RO) Theory}

Real options theory has its roots in the finance discipline (Amram \& Kulatilaka, 1999; Li, 2007). It originates from the analogy of financial options on real asset investments, a notion initially launched by Myers (1977). A financial call (put) option confers on its holder the right, but not the obligation, to buy (sell) the underlying asset at a certain price, the socalled the exercise price or strike price, during a specified time period. Making investment decisions on real assets possesses characteristics which are analogues to a financial call option ${ }^{9}$. A real option is the right, but not the obligation, to undertake future actions as to investments on real (nonfinancial) assets (Amram \& Kulatilaka, 1999). Valuing investment decisions on real assets provides expected cash flows based on the investment's sunk cost as the exercise price, and the time period to undertake the investment on the real asset (Myers, 1977; Tong \& Reuer, 2007; Trigeorgis, 1996).

\footnotetext{
${ }^{9} \mathrm{Li}$ (2007) provides detailed comparisons between real options and financial options.
} 
The discourse on real options to appraise investments has been triggered by dissatisfaction in using DCF methods such as NPV (Tong \& Reuer, 2007) which have been claimed to neglect managers' flexibilities on embedded subsequent investment opportunities (Brealey, Myers \& Allen, 2008; Myers, 1977; Tong \& Reuer, 2007). This flexibility includes options if to invest now, defer, expand, abandon or shift to another project (De Reyck, Degraeve \& Vandenborre, 2008; Trigeorgis, 1996). NPV, by contrast, presumes management is passive and unlikely to add value to an investment project evaluation even if information is subsequently received after the initial decision making (Teach, 2003).

A real options perspective enables decision makers to think about flexibilities tied to the investment project that need to be actively managed in order to reduce downside risk and or to benefit from upside opportunities. The RO analysis, however, is not a replacement of NPV approach (Van Putten \& MacMillan, 2004), but instead an enhancement. In fact, NPV is a minor RO analysis with limited application to appraise an investment that has little or no uncertainty or flexibility (Teach, 2003). Arguably, RO analysis is an extension of the NPV technique that incorporates the value of managers' flexibility to execute embedded options in a potential investment project.

\subsection{RO Analysis as an Enhancement of NPV}

As stated earlier, one of the constraints that causes unpopularity in the use of RO technique to appraise an investment project is the view that RO analysis is a 'black box' (Teach, 2003). The challenge for academics and consultants to promote the use of RO approach is to lucidly show how it works so that managers can apply it without their hands being held. Luehrman (1998a) strongly suggested that highlighting commonalities between RO approach and standard NPV as the familiar investment valuation technique will assist business practitioners to easily understand the RO framework. Conventional NPV calculates the difference between present value (PV) of cash outflows to fund the investment project and PV of cash inflows that are generated from the project. The decision to invest in the project will be executed if only the NPV calculation results in positive figures, and vice versa. Meanwhile, investing in a project similar to call options in RO technique which requires 5 (five) variables as follows (Table 3): 
Table 1. Investment Opportunity as a Call Option

\begin{tabular}{lll} 
Investment Opportunities & Variables & Call Option \\
\hline $\begin{array}{l}\text { Present values of a project's net } \\
\text { revenues /cost savings (net cash flows) }\end{array}$ & $S$ & Stock price \\
$\begin{array}{l}\text { Expenditure required to acquire the } \\
\text { project assets (investment cost) }\end{array}$ & $X$ & Exercise / strike price \\
$\begin{array}{l}\text { Length of time the decision may be } \\
\text { deferred }\end{array}$ & $t$ & Time to expiration \\
$\begin{array}{l}\text { Time value of money } \\
\text { Riskiness of the project assets }\end{array}$ & $r_{f}$ & Risk-free rate of return \\
& $\sigma^{2}$ & $\begin{array}{l}\text { Variance of returns on } \\
\text { stock }\end{array}$ \\
\hline
\end{tabular}

Source: Luehrman (1998b, p.52)

Accordingly, to use the RO approach managers need three more variables $\left(t, r f\right.$ and $\left.\sigma^{2}\right)$ on top of two variables that they already have to calculate NPV ( $S$ and $X$ ). When managers do not have the option to delay the investment or can no longer delay to invest in the project being valued, i.e. at the expiration date to make the investment decision, $\mathrm{RO}$ analysis will result in the same figures as the standard NPV calculation because $t, r f$ and $\sigma^{2}$ become meaningless. RO approach provides extra information when the managers have the ability to delay the time to invest, which is known as an option to delay or an option to wait (Luehrman, 1998a). Luehrman (1998a) further provides an illustrative study how to use RO approach with these five variables using Black-Scholes Model (please see the detailed formulae from Kodukula \& Papudesu, 2006).

Taking RO analysis to a more advanced approach, RO pricing can be mapped into a binomial lattice which looks like a dual branches' decision tree (Kodukula \& Papudesu 2006). Options valuation for a binomial lattice can be calculated using two approaches: (1) either using risk-neutral probabilities (a summary from Kodukula \& Papudesu, 2006 is provided in Appendix 2) or (2) using market-replicating portfolios (please see Copeland \& Antikarov, 2003 for further details). A case study using the Kodukula and Papudesu (2006) approach to evaluate an investment project valuation with an option to wait using (1) conventional NPV; (2) the RO 
technique with the Black-Scholes model; and (3) the RO Binomial Lattice with a risk-neutral probabilities approach, is presented in the next section.

\subsection{Why Real Options are not Popular in Practice}

For all their theoretical attractiveness to value growth projects, real options have had a difficult time catching on with managers. CFOs tell us that real options overestimate the value of uncertain projects, encouraging companies to overinvest in them. In the worst case, they grant excessively ambitious managers a license to gamble with shareholders' money (Van Putten \& MacMillan, 2004).

This reluctance stems at least in part from a suspicion that it is risky to apply valuation tools that have been developed for well-defined financial options to complex business projects. The tools oblige managers to make many simplifying assumptions and therefore, the thinking goes, they cannot fully capture a proposal's multifaceted risks and opportunities. These concerns are legitimate, but we believe that abandoning real options as a valuation model is just as bad. Companies that rely on discounted cash flow analysis for valuing their projects fall inevitably into the trap of underestimating the value of their projects and consequently don't invest enough in uncertain but highly promising opportunities.

How can managers escape this dilemma? Van Putten and MacMillan (2004) have concluded that much of the problem lies in the unspoken assumption that the real-option and DCF valuation methods are mutually exclusive. We believe this assumption is false. Managers need to integrate the two approaches if they are to make valuations that reflect the reality and complexity of their business's growth projects. Far from being a replacement for discounted cash flow analysis, real options are an essential complement because they allow managers to capture the considerable value of being able to ruthlessly abandon floundering projects before making major investments.

This is not to say that there aren't serious problems with the way managers calculate the value of real options (Van Putten \& MacMillan, 2004). There are. for a start, real options, as currently applied, focus almost exclusively on the risks associated with revenues, ignoring the risks associated with a project's costs. It is also true that typical option valuations almost always ignore the fact that the initial investments made in a project, even in one that might eventually be abandoned, often leave the company with an asset it can trade - a benefit, if you like, of failure. These are not, of 
course, the only difficulties managers encounter using real options, but they are perhaps the most fundamental sources of error, and the integrated approach we present here explicitly addresses them both.

\subsection{Integrating Options and Discounted Cash Flow}

Traditional DCF analysis relies on the straightforward principle that an investment should be funded if the net present value (NPV) of its future cash flows is positive. In other words, if it will create more value than it will cost. This works well if we are projecting future cash flows from some historical context, and we are fairly certain of future trends, but not when our estimates of future cash flows are based on a myriad of assumptions about what the future may hold. In such cases, the odds of accurately forecasting cash flows are slim.

What is more, even supposing we can arrive at a reasonably accurate base estimate for the cash flows, DCF analysis requires them to be discounted at a high rate to reflect the long odds of achieving the projected returns. As a result, all the risks of uncertainty (the possibility that actual cash flows may be much lower than forecast) are captured in the valuation but none of its rewards (the possibility that actual cash flows may be much higher than forecast). This inherent bias can lead managers to reject highly promising, if uncertain, projects.

The challenge, therefore, is to find a way to recapture some of the value lost through the conservative DCF valuation while still protecting against the considerable risks of pursuing highly uncertain projects. This is where options come in. The possibility that the project may deliver on the high end of potential forecasts, so hard for DCF analysis to take into consideration, is the primary driver of option value.

Options provide the right but not the obligation to invest in a project. Their value, therefore, is driven by the possibility of achieving a large upside gain combined with the fact that companies can usually abandon their projects before their investment in them has cost too much, thus limiting the downside. The value of an option must therefore increase as the uncertainty (and therefore the potential upside) surrounding the underlying asset increases, whether that asset is financial or "real."

Looked at in this way, it seems clear to Van Putten and MacMillan (2004) that discounted cash flow analysis and real options are complementary and that a project's total value is the sum of their values. 
The DCF valuation captures a base estimate of value; the option valuation adds in the impact of the positive potential uncertainty. One caveat though. It can hardly be stressed enough that a real-options approach can only be used on projects structured somewhat like options - that is, on projects that can be abandoned before you must commit yourself to making major financial outlays if it becomes clear that things will not go well. It would not apply, for instance, to valuing an opportunity that requires you to sink huge sums into building a new factory before you have the first inkling whether the bet will pay off.

Once one accepts the notion that a project's value has both a DCF component and an option component, it also becomes clear that the proportion of a project's total value contributed by each component will vary according to the degree of uncertainty associated with the project. In the early stages of an innovative project, the value of the DCF component will be low because of the need to use a high discount rate to adjust for the uncertain nature of future cash flows. At the same time, the real-option value will most likely be high due to that same uncertainty.

\section{Adjusting for Cost}

There are two serious problems with option valuations that must be addressed (Van Putten \& MacMillan, 2004). First, it is hard to find good proxies for the input variables the model requires. Financial options use a volatility measure derived from the easily observed historical prices of the underlying assets. But there are almost by definition no historical numbers that managers can use when trying to derive the option value of an innovative project, even to estimate the net present value of the underlying asset, let alone its volatility.

Second, even if managers succeed in finding good proxies for the optionmodel input variables, they remain vulnerable to a major conceptual error. In the current approaches to option valuation, the more variable the profits, the higher the project valuation. The variability of profits, in turn, is derived from estimates of how uncertain both revenues and costs are likely to be.

This seems reasonable but leads to an impractical result: Mindless option analysis will value a project with relatively predictable revenues but unpredictable costs more highly than a project with the same predictable revenues but with predictable costs. Van Putten and MacMillan (2004) think this is wrong. When the uncertainty about potential costs is higher than the 
uncertainty about potential revenues, cost volatility should decrease, not increase, the value of a project.

This is because, unlike revenues, where volatility can imply as much upside potential as downside, when it comes to costs, the potential for downside is generally much greater. That is, the margin by which costs overrun their estimates is almost always greater than the margin by which they underrun them.

Take, for example, a European consortium that set out to build a carbon capture plant for a projected $\$ 20$ million. It is now 15 years behind schedule, and the estimated cost is $\$ 45$ million, an overrun of $125 \%$. We do not routinely see cost savings on anything like this same scale. Indeed, with most sequestration projects, it is possible to be certain of the minimum cost, which places a floor on how far the costs can fall. But there's no corresponding ceiling for overruns.

What's more, the chance that cost uncertainty will cause overruns increases when companies look for growth opportunities in areas outside their direct expertise. Companies' appreciation of the risks of a project is systematically too optimistic. The experience of a large industrial company venturing into biotech aptly illustrates how easily the costs of a growth project can spiral out of control when a company is operating in areas far from its expertise and experience (Van Putten \& MacMillan, 2004).

For millions in R\&D dollars, the company had developed a new compound that held great promise as an additive for several consumer products. At the time we became involved, project managers had already spent money on toxicity testing and had made other large safety-related expenditures, followed by sophisticated consumer testing, all of which indicated that the compound held considerable potential to command high prices. But the firm had not yet tried to ramp up manufacturing to produce the compound in commercial quantities. Based on long years of experience, management simply guessed that it could be produced for approximately $\$ 20$ per unit and paid no more attention to the costs of commercial production. 
It turned out, though, that the manufacturing process was hugely more difficult than anticipated. The cost to produce the compound was going to be in the order of hundreds of dollars per unit, which put it outside the range of commercial viability.

Had company managers taken cost volatility into account effectively, they would have managed the project differently. First, they would have realised sooner that the manufacturing process represented the greatest part of the uncertainty surrounding the project. That would have encouraged them to switch the business development effort from product R\&D toward process $R \& D$, so that they would first have understood manufacturing feasibility and only afterwards have investigated consumer demand. Second, considering cost volatility would also have produced a much smaller total project value, which would have led them to curtail investment in the project at an earlier stage, saving them millions of dollars.

Since costs are volatile in a different way than revenues are, the formula for determining option value needs to be adjusted when cost volatility is greater than revenue volatility. In principle, one should compute an adjusted option value (AOV) that reflects the negative nature of cost uncertainty by separately calculating the option value of the revenues and then subtracting the option "value" of the costs.

In practice, however, there is no need to compute the impact of cost volatility separately from the impact of revenue volatility. There is a simpler approach that is good enough for inferring the AOV of a project, when necessary, and that has the advantage of being simple and quick. Simple and quick is what's needed for most valuations: In any firm with far more projects under consideration than funds or staff to support them, managers need not have a precise value for a specific project; they need only know whether a project is preferable to other projects competing for the company's limited funds and talent.

So rather than being concerned with whether a valuation is precise, managers should look at it as a yardstick that allows them to choose the best among competing projects. If they feel sure that all the projects applying for funds are being valued in the same way, they can be reasonably confident that they will, on average, select and assign resources to the best ones. 


\section{Carbonvestment Project Appraisal using NPV and RO Approaches: A Case Study}

Making carbonvestments provide real options when managers acquire the right, but not the obligation, to undertake further action. This is highlighted in the firm PowerCo, for which actual data was obtained by the authors to demonstrate the practical application of the RO approach in a real business setting. ${ }^{10}$

PowerCo is a large Australian electricity generator, which generates the bulk of its electricity from burning coal. It will be a liable party under the proposed Carbon Pollution Reduction Scheme (CPRS) ${ }^{11}$ and therefore will need to surrender permits equivalent to its annual emissions or face fines. The aim of the company is to meet its emissions liability for the lowest weighted average cost per tonne of $\mathrm{CO}_{2}$ emitted, whilst adhering to PowerCo's strategic imperatives.

The company's revenues are expected to be $\$ 0.8$ billion and are expected to grow. Figure 1 shows the company's projected revenue growth. Note that the High/Low revenue scenarios shown equal a $+/-3 \%$ of medium revenue and is in line with high/low scenarios for carbon emissions given in Table 4. The company's EBIT follows the medium revenue scenario.

\footnotetext{
10 The data was given to authors by consulting firm Booz Allen that PowerCo was a client of. For confidentiality purposes the name of company was withheld, and the data was slightly modified.

${ }^{11}$ CPRS is the Australian carbon trading which was proposed to commence in 2013 (Australian Government: Department of Climate Change and Energy Efficiency 2010).
} 
Management Accounting Frontiers 2 (2019) 31 - 68

Figure 1. PowerCo's Past and Projected Revenue Growth (2006-2013)

PowerCo Revenue: FY06 to FY13

$(\$ B)$



PowerCo's emissions are estimated to be 10.9 million tonnes of $\mathrm{CO}_{2}$ in 2010 financial year, and the strategic target is to decrease emissions to 10.42 million tonnes of $\mathrm{CO}_{2}$ by the financial year 2013. The three possible annual emission estimates scenarios are as follows:

Table 4. PowerCo's Estimated Carbon Emissions Scenarios

\begin{tabular}{lccc} 
Projected Emissions & $\mathbf{2 0 1 1}$ & $\mathbf{2 0 1 2}$ & $\mathbf{2 0 1 3}$ \\
\hline Low Estimate & 10.48 & 10.27 & 10.11 \\
Med Estimate & 10.8 & 10.58 & 10.42 \\
High Estimate & 11.12 & 10.9 & 10.74 \\
\hline
\end{tabular}


The CEO of PowerCo sees the emissions trading scheme as a major challenge but is nevertheless committed to reducing emissions. Historically, PowerCo has taken a small interest in both renewable energy and energy efficiency and has developed a portfolio of renewable energy assets, including solar, wind and hydro, currently contributing about $10 \%$ of its capacity. Over the past few years, it has also made significant investments in reducing $\mathrm{CO}_{2}$ emissions from coal burning, with more projects planned. Consequently, the level of emissions has been slightly below industry average.

The CEO has a firm mandate from the Board to ensure that when a CPRS is introduced, all emissions are covered by permits - this is thus a mandatory requirement for PowerCo. As it is not a trade exposed industry, PowerCo is not eligible for any free permits and must therefore meet its full emission liability through purchased permits. As such, PowerCo's carbon strategy is two-fold: primarily, to develop cleaner coal technologies - at least two abatement projects must focus on cleaner coal burning; and secondarily, to further development of its renewable/low carbon energy portfolio - at least one abatement project must focus on renewable energy/low carbon fuels

The two levers available to PowerCo to meet its strategic objectives of covering its emissions liability at the lowest possible cost are: (1) emissions reduction through new projects/technologies; and (2) buying an optimal combination of permits and credits to meet any shortfall. The first lever involves investing in projects to reduce carbon emissions from traditional technologies or increase energy output from low-emission technologies. Some projects will have a lead time to be considered (results may take years to realise) as well as a probability of success attached to them. There is therefore a risk associated with investing in these projects, instead of purchasing permits. The second lever involves needing to determine optimal combination of permits to purchase from the available sources such as.:

- Auction - average price $=$ AU $\$ 25$

- Secondary market - current price $=$ AU $\$ 28$

- International carbon market - via investments in actual projects (called primary international credits) where there is a very real risk of failure; or by buying from exchanges where there is no delivery risk (called secondary international credits).

It must be emphasised that the purchase of primary international credits via investments in actual projects has an associated risk, as the project has 
not yet been completed so the abatement results are not assured. There are also only a limited number of primary international credits available, especially via Clean Development Mechanism (CDM) ${ }^{12}$ projects. Their price is therefore significantly below the secondary international credits, which are guaranteed delivery.

PowerCo has several emission-reduction projects in the pipeline, which will enable its total CPRS liability to be reduced. It is investigating the viability of these projects irrespective if a CPRS is introduced in 2013 in Australia (as expected) or not. One such project is to improve its operations by the implementation of technologies to improve efficiency of electricity generated in the existing coal-fired units. Another project is a fuel switch as PowerCo currently generates the bulk of its electricity from a major coal plant. This initiative involves a partial transformation of some units to gas fired plants. Three projects are also available for investment in order to generate primary international credits: (1) a wind farm in China; (2) the conversion of methane to carbon dioxide at a pig farm in Indonesia ${ }^{13}$; and (3) the reduction of $\mathrm{N}_{2} \mathrm{O}$ (nitrous oxide) emissions at a fertiliser plant in Kazakhstan. The estimated emissions reductions and their associated probabilities of success are given below (Table 5).

\footnotetext{
${ }^{12}$ Clean Development Mechanism (CDM) is an investment project undertaken by industrialised countries to lessen GHG emissions in developing countries, as one of suggested mechanisms under the Kyoto Protocol.

${ }^{13} \mathrm{Co}_{2}$ being the lesser GHG pollutant.
} 
Table 5. PowerCo's Carbonvestment Alternatives

\begin{tabular}{lll} 
Lever 1: Local Projects & $\begin{array}{l}\text { Estimated Emission } \\
\text { Reduction }\end{array}$ & $\begin{array}{l}\text { Estimat } \\
\text { of succe }\end{array}$ \\
\hline A. Operational Efficiency & $5 \%$ & $80 \%$ \\
B. Fuel Switch & $20 \%$ & $50 \%$
\end{tabular}

\section{Lever 2: International Abatement Projects}
A. Wind farm
200,000 tonnes
B. Methane Conversion
300,000 tonnes
$1,000,000$ tonnes
C. $\mathrm{N}_{2} \mathrm{O}$ Reduction (in $\mathrm{CO}_{2}$ )

\begin{tabular}{ll}
200,000 tonnes & $85 \%$ \\
300,000 tonnes & $60 \%$ \\
\hline $1,000,000$ tonnes & $25 \%$
\end{tabular}

Estimated $\mathrm{CO}_{2}$

Abatement

PowerCo estimates (by consensus obtained from its managers and outside consultants) that the price of International Carbon Credits (e.g. CERs) is expected to decrease by around A $\$ 3.00$ between 2010 and 2012, especially as are affected by exchange rate fluctuations that have been significant since the weakening of the United States dollar (USD). PowerCo estimates of 2011 prices vary from $\mathrm{A} \$ 10$ to $\mathrm{A} \$ 30$, with an average of A\$20 (a volatility of 37.39\% estimated using logarithmic cash flow returns methods).

Please note that these forecasts do not factor in potentially significant developments such as the introduction of a new national/regional trading scheme which could significantly increase the supply of credits on the international market, and therefore reduce price. These forecasts are significant below what the company predicted at the start of 2010, when the Australian dollar (AUD) was trading at 0.75 USD. The estimates for the case study of International Carbon Credits were obtained in October 2010 when the AUD was at parity with the USD.

PowerCo is looking closely at the methane conversion project at a pig farm in Indonesia, which will qualify as a CDM project to generate CERs (Certified Emissions Reductions) within a 5-year period [ $t$ : time to expiration $=5$ years $]$. The financing for the project will be mainly from Australia, and PowerCo has calculated its cost of capital below (Table 6). 
Management Accounting Frontiers 2 (2019) $31-68$

Table 6. PowerCo's Financing Costs

\begin{tabular}{ll}
\hline Exp Market Return $\left(\mathrm{R}_{\mathrm{m}}\right)$ & 0.14 \\
Exp Risk Free Rate $\left(\mathrm{R}_{\mathrm{f}}\right)$ & 0.06 \\
Company Beta & 0.65 \\
Cost of Equity $\left(\mathrm{K}_{\mathrm{e}}\right)$ & 0.112 \\
Cost of Debt $\left(\mathrm{K}_{\mathrm{d}}\right)$ & 0.11 \\
Debt/Equity Ratio $(\mathrm{B} / \mathrm{S})$ & 0.46 \\
WACC $\left(\mathrm{K}_{\mathrm{o}}\right)$ & $11.11 \%$ \\
\hline
\end{tabular}

Table 7. PowerCo - Methane Conversion Project Cost-Benefit Estimates

$\begin{array}{llllll}\text { Year } 0 & \text { Year } 1 & \text { Year } 2 & \text { Year } 3 & \text { Year } 4 & \text { Year } 5\end{array}$

\begin{tabular}{|c|c|c|c|c|c|c|}
\hline & Year 0 & Year 1 & Year 2 & Year 3 & Year 4 & Year 5 \\
\hline $\begin{array}{l}\text { Fixed } \\
\text { Investment }\end{array}$ & $(\$ 13 \mathrm{~m})$ & $(\$ 3 m)$ & $(\$ 500 k)$ & $(\$ 500 \mathrm{k})$ & $(\$ 250 \mathrm{k})$ & $(\$ 125 \mathrm{k})$ \\
\hline $\begin{array}{l}\text { Working } \\
\text { Capital } \\
\text { Investment } \\
\text { and Recovery }\end{array}$ & & $(\$ 500 \mathrm{k})$ & & & & $\$ 500 \mathrm{k}$ \\
\hline $\begin{array}{l}\text { Carbon } \\
\text { Emissions } \\
\text { reductions in } \\
\text { Tonnes }\end{array}$ & & $180 \mathrm{k}$ & $180 \mathrm{k}$ & $180 \mathrm{k}$ & $180 \mathrm{k}$ & $180 \mathrm{k}$ \\
\hline $\begin{array}{l}\text { Expected } \\
\text { Carbon Price }\end{array}$ & & $\$ 25$ & $\$ 20$ & $\$ 30$ & $\$ 20$ & $\$ 25$ \\
\hline
\end{tabular}

The cost of the investment is spread over a number of years, as are the cost savings/revenues that are estimated to be generated by generating trading in international CERs. The estimated investment costs, the estimated carbon emissions reductions in tonnes (using a 60\% probability of success) and the estimated CER price is given below (Table 7). 
Management Accounting Frontiers 2 (2019) $31-68$

Table 8. The Value of Option to Delay for PowerCo

\begin{tabular}{llll} 
& NPV & Black-Scholes & Binomial Method \\
\hline $\begin{array}{l}\text { Input Data } \\
\begin{array}{l}\text { Strike price } \\
\text { (investment cost) } \\
\text { (million) }\end{array}\end{array}$ & $\$ 16,862,220$ & $\$ 16,862,220$ & $\$ 16,862,220$ \\
$\begin{array}{l}\text { Present value of } \\
\text { future cash flows } \\
\text { (million) }\end{array}$ & $\$ 15,923,009$ & $\$ 15,923,009$ & $\$ 15,923,009$ \\
$\begin{array}{l}\text { Volatility (annual) } \\
\text { Risk-free rate of } \\
\text { return (annual) }\end{array}$ & - & & \\
$\begin{array}{l}\text { Time to expiration } \\
\text { (years) }\end{array}$ & - & $37.79 \%$ & $37.79 \%$ \\
$\begin{array}{l}\text { Calculated Parameters } \\
\text { d1 }\end{array}$ & $6 \%$ & $6 \%$ \\
$\begin{array}{l}\text { d2 } \\
\text { Up factor }(u)\end{array}$ & 5 & 5 \\
$\begin{array}{l}\text { Down factor }(d) \\
\text { Risk-neutral probabilities }(p)\end{array}$ & & \\
$\begin{array}{l}\text { Results } \\
\text { NPV }\end{array}$ & & 0.710 & -0.135 \\
$\begin{array}{l}\text { RO value } \\
\text { Value added }\end{array}$ & $(\$ 939,211)$ & $(\$ 939,211)$ & - \\
\hline
\end{tabular}

The conventional DCF estimate using an appropriate risk-adjusted discount rate $\left(\mathrm{K}_{\mathrm{o}}\right)$ reveals that the present value $(\mathrm{PV})$ of expected future cash flows for the CERs that can be generated from the CDM project will be approximately $\$ 16$ million [ $S_{o}$ : current asset value $\left.=\$ 15,923,009\right]$. Whereas the investment value to implement the CDM project is approximately 17 million $[X$ : strike price $=\$ 16,862,220]$. The uncertainty or annual volatility of the CER price in a carbon market is assumed to be approximately $37 \%[\sigma$ : volatility $=37.39 \%]$ and the risk-free rate over the following five-year period as estimated above is $6 \%\left[r_{f}\right.$. risk-free rate $=$ $6 \%]$. 
Figure 2. Option Valuation using Binomial Lattice for PowerCo (all numbers are rounded in $\$$ million)

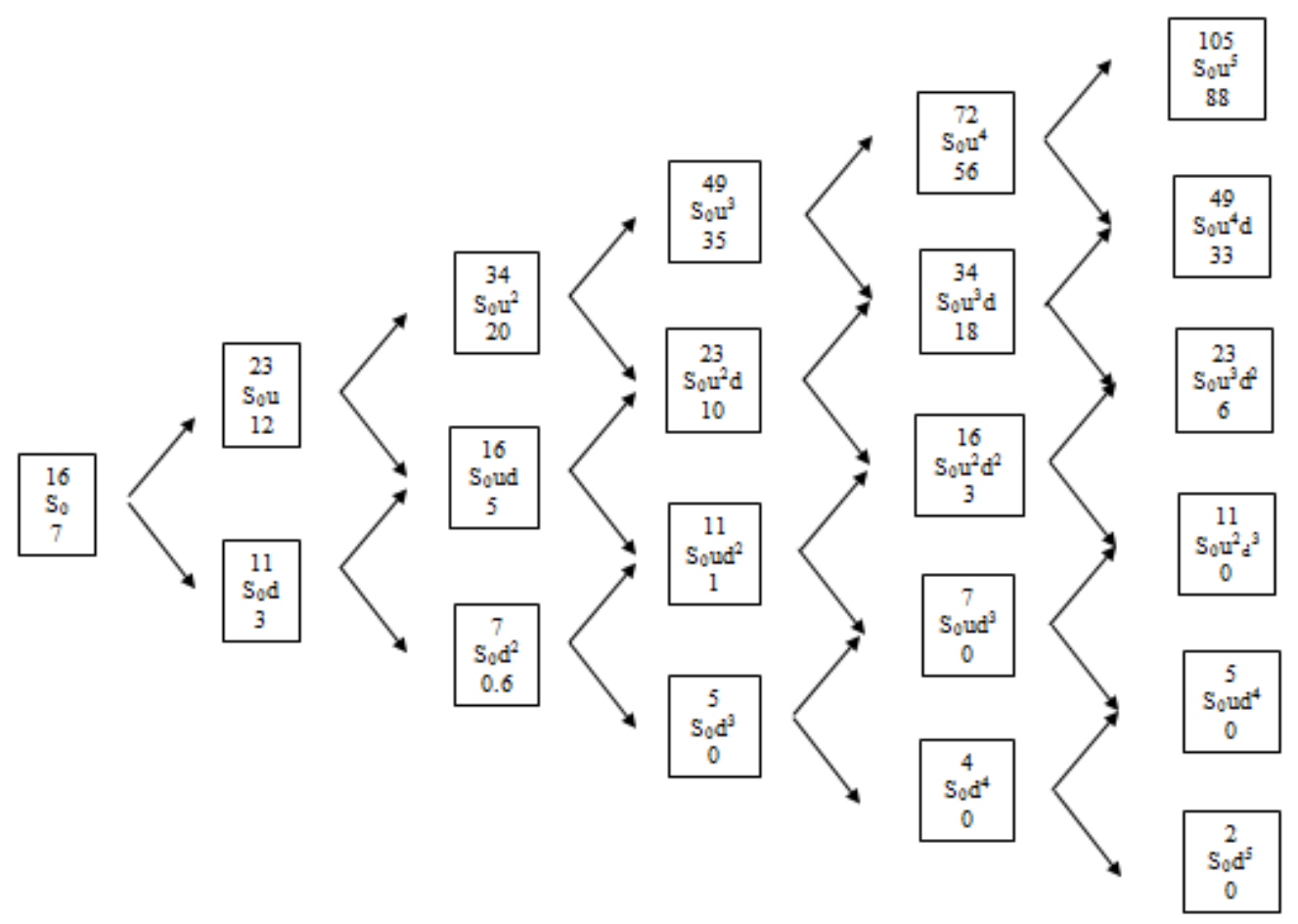

Quantifying option to delay values using Black-Scholes model is simpler than using Binomial method. However, the Binomial approach offers clearer logic and strategic pathways for decision makers as depicted using one-year time steps in as seen in Figure 2.

The upper numbers on the binomial lattice are the estimated values of carbon credits from the CDM project (CERs) over the five-year option life. It starts with current value $\left(\mathrm{S}_{0}\right)$ of $\$ 15,923,009$, which is similar to standard PV of cash inflows from CERs trading under NPV analysis. In the first time step, the expected value of CERs will be either up to $\$ 23,234,661$ $\left(\mathrm{S}_{0} \mathrm{u}\right)$ or down to $\$ 10,912,241\left(\mathrm{~S}_{0} \mathrm{~d}\right)$ at the end of the first year, and so on. Meanwhile the bottom numbers represent option-to-wait values at each node.

Starting from the left, if PowerCo exercised the CDM project by investing $\$ 16,862,220$, the cash flows generated will be $\$ 15,923,009$ (the 
asset value of $S_{0}$ ), resulting in net loss of $\$ 939,211$. As stated earlier, investing right away at time 0 gives the similar result as NPV analysis. To keep waiting to exercise the project offers a value of $\$ 6,544,412$. Hence, it is worth deferring the CDM project at this stage. Moving the analysis on to the intermediate node at the end of year 3 with 1 down factor $\left(\mathrm{S}_{0} \mathrm{u}^{2} \mathrm{~d}\right)$, to invest $\$ 16,862,220$ in the CDM project will generate carbon credits' worth of $\$ 23,234,661$, resulting in a net payoff of $\$ 6,372,441$. Keeping the option alive shows a higher asset value of $\$ 9,670,471$, hence one would continue waiting at this node. At the last time step, incorporating the downstream risk at node $\mathrm{S}_{0} \mathrm{u}^{4} \mathrm{~d}$, the expected carbon credit value is $\$ 49,471,917$ if PowerCo exercises the CDM project. PowerCo will obtain a net payoff of $\$ 15,747,476$ by investing $\$ 16,862,220$. RO logic suggests executing the CDM project as the valuation turns out to be favourable as this node. Here, PowerCo can no longer delay the investment project as the option will expire after the five-year period. The option-to-wait values at the end of the option life will become worthless. This case-based analysis clearly reveals that taking into account managerial flexibility to delay the investment and handle the uncertainty of the investment project facilitates better informed decision making.

\section{Conclusion}

The Carbon Pollution Reduction Scheme (or CPRS) that we have used as a case study was a cap-and-trade emissions trading scheme for anthropogenic greenhouse gases proposed by the Rudd government (in Australia), as part of its climate change policy, which had been due to commence in Australia in 2010. It marked a major change in the energy policy of Australia. The policy began to be formulated in April 2007 when the federal Labor Party was in Opposition. The six Labor-controlled states commissioned an independent review on energy policy, the Garnaut Climate Change Review, which published several reports. After Labor won the 2007 federal election and formed government, it published a Green Paper on climate change for discussion and comment. The Federal Treasury then modelled some of the financial and economic impacts of the proposed CPRS scheme.

The Rudd government published a final White Paper on 15 December 2008 and announced that legislation was intended to take effect in July 2010. However, the legislation for the CPRS (aka ETS) failed to gain the numbers in the Senate and was twice rejected creating a double dissolution election trigger. A bitter political debate within the Coalition opposition 
saw opposition leader Malcolm Turnbull lost the leadership to the antiCPRS Tony Abbott. The Rudd government did not call an election and in April 2010, Rudd deferred plans for the CPRS.

After the 2010 federal election, the Gillard Government was able to get the Carbon Pricing Mechanism (CPM) passed into law as part of the Clean Energy Futures Package (CEF) in 2011, and became effective on 1 July 2012.

Due to the great deal of policy uncertainty surrounding the scheme, organizations in Australia responded in a rather informal and tepid manner and largely withheld from making any large-scale investments in emissions reductions technology during the scheme's operation.

Despite the realities of the lukewarm response that the CPRS received in Australia, we have demonstrated that RO analysis offers a strategic way to incorporate carbon exposure in investment decision making. Carbonvestment opportunities provide real options when managers acquire the right, but not the obligation, to undertake further action. RO insights enable the identified investment options to be optimally valued for investment decision making in the carbonomics era, which was demonstrated to be overlooked by conventional NPV analysis in the case study provided. Accordingly, RO theory may shed new light to improve understanding of uncertainty, and the flexibility and strategy that need to be addressed by carbon emissions regulated firms in allocating financial resource investments in a carbon constrained economy.

We have demonstrated that the practical applicability of the RO approach in the share markets can be duplicated in the carbon trading markets. In the share markets there are set parameters within which share prices can move, enabling one to model possible options if a share price hits a certain value. The RO approach was not popular in practice as standard investment projects do not have such value parameters, as the market for such projects is illiquid. However, with the introduction of a CPRS/ETS or similar future pricing structure, these market-value parameters will be present, thus we have demonstrated the how the RO approach can be used as a very robust and practical approach to investment appraisal in the carbonomics era. 


\section{References}

Amram, M. and Kulatilaka, N., (1999), Real Options: Managing Strategic Investment in an Uncertain World, Harvard Business School Press, Boston.

Barber, B. R., (2007), "Climate Change and the Politics of Interdependence", Schumacher Centre for a New Economics, available at https://centerforneweconomics.org/publications/climate-change-and-thepolitics-of-interdependence/ [Accessed 20 December 2019]

Bebbington, J. and Larrinaga, C., (2008), "Carbon Trading: Accounting and Reporting Issues", European Accounting Review, Vol. 17 No. 4, pp. 697-717.

Bennaouna, K, Meredith, G. G. and Marchant, T., (2010), "Improved Capital Budgeting Decision Making: Evidence from Canada", Management Decision, Vol. 48 No. 2, pp. 225-247.

Brealey, R. A., Myers, S. C. and Allen, F., (2008), Principles of Corporate Finance, 9th Edn., McGraw-Hill/Irwin, Boston.

Callon, M., (2008), "Civilizing Markets: Carbon Trading between In-Vitro and In-Vivo Experiments", Accounting, Organizations and Society, Vol. 34 No. 3-4, pp. 535-548.

Cook, A., (2009), "Emission Rights: From Costless Activity to Market Operations", Accounting, Organizations and Society, Vol. 34 No. 3-4, pp. 456-468.

Copeland, T. and Antikarov, V., (2003), Real Options: A Practitioner's Guide, Thomson, New York.

Damodaran, A., (2002), Investment Valuation: Tools and Techniques for Determining the Value of Any Asset, 2nd Edn., Wiley, New York.

Damodaran, A., (2011), Applied Corporate Finance, 3rd Edn., John Wiley \& Sons, Hoboken.

De Reyck, B., Degraeve, Z. and Vandenborre, R., (2008), "Project Options Valuation with Net Present Value and Decision Tree Analysis", European Journal of Operational Research, Vol. 184 No. 1, pp. 341-355.

Dixit, A. K. and Pindyck, R. S., (1995), "The Options Approach to Capital Investment”, Harvard Business Review, Vol. 73 No. 3, pp. 105-115. 
Egenhofer, C., (2007), "The Making of the EU Emissions Trading Scheme: Status, Prospects and Implications for Business", European Management Journal, Vol. 25 No. 6, pp. 453-464.

Engels, A., (2009), "The European Emissions Trading Scheme: An Exploratory Study of How Companies Learn to Account for Carbon", Accounting, Organizations and Society, Vol. 34 No. 3-4, pp. 488-498.

Engels, A., Knoll, L. and Huth, M., (2008), "Preparing for the "Real" Market: National Patterns of Institutional Learning and Company Behaviour in the European Emissions Trading Scheme (EU ETS)", European Environment: The Journal of European Environmental Policy, Vol. 18 No. 5, pp. 276-297.

Freedman, M. and Jaggi, B., (2005), "Global Warming, Commitment to the Kyoto Protocol and Accounting Disclosures by the Largest Global Public Firms from Polluting Industries", The International Journal of Accounting, Vol. 40 No. 3, pp.215-232.

Haka, S. F., (2007), "A Review of the Literature on Capital Budgeting and Investment Appraisal: Past, Present, and Future Musings", in C. S. Chapman, A. G. Hopwood and M. D. Shields, Handbook of Management Accounting Research, Vol. 2, Elsevier, North Holland, pp. 697-728.

Harriss, R. C., Paton, D. and Elsayed, K., (2010), "What We're Watching... in Green Business", Harvard Business Review, Vol. 88 No. 5, pp. 24-30.

Hoffmann, V. H., (2007), "EU ETS and Investment Decisions: The case of the German Electricity Industry", European Management Journal, Vol. 25 No. 6, pp. 464-474.

Kodukula, P. and Papudesu, C, (2006), Project Valuation Using Real Options: A Practitioner's Guide, J. Ross Publishing, Plantation.

Kundu, D., (2006). "Financial Aspects of Carbon Trading", The Chartered Accountant, Vol. 54 No. 10, pp. 1496-1500.

Laurikka, H., (2006), "Option Value of Gasification Technology within an Emissions Trading Scheme”, Energy Policy, Vol. 34 No. 18, pp. 39163928.

Laurikka, H. and Koljonen, T., (2006), "Emissions Trading and Investment Decisions in the Power Sector - A Case Study in Finland", Energy Policy, Vol. 34 No. 9, pp. 1063-1073. 
Li, J. (2007), "Real Options Theory and International Strategy: A Critical Review", in Advances in Strategic Management, Vol. 24, pp. 67-101.

Luehrman, T. A., (1998a), "Strategy as a Portfolio of Real Options", Harvard Business Review, Vol. 76 No. 5, pp. 89-99.

Luehrman, T. A., (1998b), "Investment Opportunities as Real Options: Getting Started on the Numbers", Harvard Business Review, Vol. 76 No. 4, pp. 51-67.

MacKenzie, D., (2009), "Making Things the Same: Gases, Emission Rights and the Politics of Carbon Markets", Accounting, Organizations and Society, Vol. 34 No. 3-4, pp. 440-455.

Murphy, M., (2009), "Companies Slow to Act on Emissions", The Sydney Morning Herald, available at https://www.smh.com.au/business/ companies-slow-to-act-on-emissions-20090720-dqtw.html [Accessed 20 December 2019]

Myers, S. C., (1977), "Determinants of Corporate Borrowing", Journal of Financial Economics, Vol. 5 No. 2, pp. 147-175.

Okereke, C., (2007), "An Exploration of Motivations, Drivers and Barriers to Carbon Management: The UK FTSE 100", European Management Journal, Vol. 25 No. 6, pp. 475-486.

Parkinson, G., (2010), "Power Shift: The Clean Energy Debate", The Deal, May 2010, pp. 24-33.

Pinkse, J. and Kolk, A., (2009), International Business and Global Climate Change, Routledge, New York.

Pollard, S., (1965), The Genesis of Modern Management: A Study of the Industrial Revolution in Great Britain, Harvard University Press, Cambridge.

Ratnatunga, J., (2007), "An Inconvenient Truth about Accounting", Journal of Applied Management Accounting Research, Vol. 5 No. 1, pp. 1-20.

Ratnatunga, J. and Balachandran, K. R., (2009), "Carbon Business Accounting: The Impact of Global Warming on the Cost and Management Accounting Profession", Journal of Accounting, Auditing \& Finance, Vol. 24 No. 2, pp. 333-355. 
Ratnatunga, J., Jones, S. and Balachandran, K. R., (2010), “The Valuation and Reporting of Organizational Capability in Carbon Emissions Management", Accounting Horizons, Vol. 25 No. 1, pp.127-147.

Roeser, F. and Jackson, T., (2002), "Early Experiences with Emissions Trading in the UK", Greener Management International, Vol. 39, pp. 4354.

Schultz, K. and Williamson, P., (2005), "Gaining Competitive in a CarbonConstrained World: Strategies for European Business", European Management Journal, Vol. 23 No. 4, pp. 383-391.

Schumacher, E. F., (1997), This I Believe, and Other Essays, Green Books, Cambridge.

Smith, J. E. and Nau, R. F., (1995), "Valuing Risky Projects: Option Pricing Theory and Decision Analysis", Management Science, Vol. 41 No. 5, pp. 795-816.

Snedeker, S. M., (2003), "What is the Precautionary Principle? How is it Taking Shape Nationally and Globally?' The Ribbon, Vol. 8 No. 3, pp. 15.

Teach, E., (2003), “Will Real Options Take Root?”, CFO, Vol. 19 No. 9, p. 73.

Tong, T. W. and Reuer, J. J., (2007), "Real Options in Strategic Management", in Advances in Strategic Management, Vol. 24, pp. 3-28.

Trigeorgis, L. (1996), Real Options: Managerial Flexibility and Strategy in Resource Allocation, MIT Press, Cambridge.

Tyler, E. and Chivaka, R., (2011), "The Use of Real Options Valuation Methodology in Enhancing the Understanding of the Impact of Climate Change on Companies", Business Strategy and the Environment, Vol. 20 No. 1, pp. 55-70.

Van Putten, A. B. and MacMillan, I. C., (2004), "Making Real Options Really Work", Harvard Business Review, Vol. 82 No. 12, pp. 134-141.

Yavas, A. and Sirmans, C., (2005), "Real Options: Experimental Evidence", Journal of Real Estate Finance and Economics, Vol. 31 No. 1, pp. 27-52. 


\section{Appendix 1. Black-Scholes Equation}

The Black-Scholes equation (Kodukula \& Papudesu, 2006, p. 67):

$C=N\left(d_{1}\right) S_{0}-N\left(d_{2}\right) X \exp (-r t)$

Where

$C=$ value of the call option

$S_{0}=$ current value of the underlying asset

$X=$ cost of investment or strike price

$r=$ risk-free rate of return

$t=$ time to expiration

$d_{1}=\left[\ln \left(S_{0} / X\right)+\left(r+0.5 \sigma^{2}\right) T\right] / \sigma \sqrt{ } T$

$d_{2}=d_{1}-\sigma \sqrt{ } T$

$\sigma=$ annual volatility of future cash flows of the underlying asset

$N\left(d_{1}\right)$ and $N\left(d_{2}\right)=$ the values of the standard normal distribution at $\mathrm{d} 1$ and d2 (available in Microsoft Excel ${ }^{\circledR}$ as a function). 


\section{Appendix 2. Binomial Lattice Method}

Steps to value RO using Binomial Lattice method (adopted from Kodukula \& Papudesu 2006, pp. 72-79):

1. Calculate the three option value parameters as follows:

a. Up factor $(u)=\exp (\sigma \sqrt{ } \delta t)$

Where,

$\sigma=$ the volatility $(\%)$ represented by the standard deviation of natural logarithm of the underlying free cash flow returns

$\delta t=$ the time associated with each time step of the binomial tree

b. Down factor $(d)=1 / u$

c. The risk-neutral probability $(p)=\frac{\exp (r \delta t)-d}{u-d}$

Where

$r=$ the risk-free interest rate or rate of return on a riskless asset during the life of the option

2. Build the binomial tree in two steps:

a. Calculate the asset values: start with $S_{0}$ and multiply it by the up factor and the down factor to obtain $S_{0} u$ and $S_{0} d$ respectively. Continue in a similar fashion until the last time steps.

b. Calculate the option values with backward induction:

- Start with the last time step, the option value $=$ the expected asset value - the exercise price

- For the intermediate node, the option value = the discounted (at the risk-free rate) weighted average of potential future option values using the risk-neutral probability.

For instance, the option value at node

$S_{0} \mathrm{u}^{4}=\left[p\left(S_{0} u^{5}\right)+(1-\mathrm{p})\left(S_{0} u^{4} d\right)\right] * \exp (-r \delta t)$ 